\title{
Thermal and moisture limits of grain maize in Europe: model testing and sensitivity to climate change
}

\author{
G. J. Kenny*, P. A. Harrison \\ Environmental Change Unit, University of Oxford, Oxford OX1 3TB, United Kingdom
}

\begin{abstract}
Grain maize is a crop that is limited by both temperature and moisture availability in Europe. Thermal requirement data for different phases of development allowed the sensitivity of the European growing season to climate change to be tested. Within the thermal limits to crop development there are clearly differences in crop water relations, depending on soil water holding capacity, precipitation amount and potential evapotranspiration (PET). These factors are combined together in a crop-specific water balance model. The sensitivity of grain maize to changes in temperature and precipitation was tested with the model. Uncertainties are evident in the use of the Thornthwaite method of calculating PET. However, it is clear that increased temperatures will lead to increased PET. A temperature change of $+2{ }^{\circ} \mathrm{C}$ has a significant negative effect on the water balance output. A $10 \%$ increase in precipitation offsets this negative effect. These effects are partly offset by a shortened growing season, which leads to a lower accumulated water deficit. The result is compounded when the timing of sowing is taken into account. There is a net benefit from being able to sow earlier under a warmer climate. While this offers an important adaptation strategy it remains clear that conditions will continue to be water limited for grain maize production in southern Europe, and in many areas of expanded thermal potential.
\end{abstract}

\section{INTRODUCTION}

A range of climatic factors affect crop development and growth (Monteith 1981). In Europe the main climatic constraints to grain maize (Zea mays L.) are the effects of temperature on development, and water on growth and yield. Thermal limits to development can be defined by a minimum thermal accumulation above a base temperature referred to as the thermal time (Monteith 1981) or effective temperature sum (ETS) (Carter et al. 1991). Temperature is the major constraint to the expansion of grain maize into higher latitudes. Carter et al. (1991) demonstrate that even a $1{ }^{\circ} \mathrm{C}$ rise in mean temperature would lead to a significant expansion in the northern limit of suitability based on a minimum ETS requirement.

\footnotetext{
- Present address: Centre for Environmental and Resource Studies (CEARS), University of Waikato, Private Bag 3105 , Hamilton, New Zealand
}

Availability of water is a predominant limiting factor to growth of grain maize in southern Europe. Virtually all of the grain maize crop in Spain and Greece is irrigated (Bignon 1990). The demand for water by a crop and its availability may change under a possible warmer climate. Knowledge of how these factors may change will be critical to planning future use of water resources. This will be crucial in countries such as Spain, where there is already concern over loss of ground-water to irrigation (Oliver, Inst. Hydrology, Wallingford, UK, pers. comm. 1991).

While the northern and southern limits to grain maize can be coarsely defined by temperature and precipitation respectively there is in reality a dynamic interaction between the two (both temporally and spatially). Temperature influences both the timing and duration of the growing season. Both of these factors will affect the balance between the amount of precipitation received by a crop and potential evapotranspiration (PET) from the crop surface. 
This paper provides an evaluation of the climatic factors which set the limits for grain maize suitability in Europe. Consideration is given firstly to the influence of temperature on crop suitability and growing season length. A significant part of the subsequent analyses deals with the development and testing of a water balance model for the maize crop. This allows for greater consideration of the interactions between temperature and precipitation in determining crop suitability. The final sections of the paper incorporate analyses of the sensitivity of grain maize to climate change.

\section{METHODS OF ASSESSMENT}

The current agroclimatic database consists of average monthly temperature and average monthly precipitation (1951 to 1980) and soils data, including estimates of available water holding capacity (AWC) (Groenendijk 1989). These data have been interpolated to a $1^{\circ}$ longitude by $0.5^{\circ}$ latitude grid across Europe, as described in Carter et al. (1991).

Seasonal temperature accumulations were calculated using an effective temperature sum (ETS) formula (Carter et al. 1991). Temperature data were also used to calculate potential evapotranspiration (PET) using the Thornthwaite method. A cropspecific water balance was also derived (FAO 1986). Every attempt was made to validate the derived data (referred to as agroclimatic indices). These are discussed in full in the relevant sections. Model validation was carried out for baseline (1951 to 1980) conditions. Analyses were made by both geographically coding the agroclimatic indices and mapping them, as described in Carter et al. (1991), and by graphically and statistically evaluating the uncoded output.

Having evaluated the indices for baseline conditions the sensitivity of grain maize to climate change was tested. Systematic adjustments were made to the input variables in order to gauge the level of change required to give a significant change in model output. It is stressed here that, for assessing the impacts of climate change, the critical need is to determine the degree to which crops are sensitive to change in selected climatic variables. This is particularly important given the uncertainty over general circulation model (GCM) projections of climate change.

\section{TEMPERATURE LIMITS TO DEVELOPMENT}

Temperature limits to crop development are normally defined by a critical accumulation above a base temperature, either between development stages or over the growing season. An empirical method of calculating thermal time from monthly data, referred to as effective temperature sum (ETS), was used by Carter et al. (1991) to map the northern limit of grain maize in Europe based on an annual accumulation of $850^{\circ} \mathrm{C}$ days above a base of $10^{\circ} \mathrm{C}$ (Goudriaan 1988). The standard formula for calculation of thermal time is:

$$
\begin{aligned}
& \text { Thermal time }=\sum_{i=1}^{n}\left(T_{i}-T_{b}\right){ }^{\circ} \mathrm{C} \text { days } \\
& \quad \text { for } n \text { days when } T_{j}>T_{\mathrm{b}}
\end{aligned}
$$

where $T_{1}$ is the mean temperature of Day $i$ and $T_{\mathrm{b}}$ is the base temperature for the crop in question.

The minimum temperature for germination of maize is in the range 7.8 to $10.0^{\circ} \mathrm{C}$ (Hellmers \& Warrington 1982), although the base temperature most commonly used is $10^{\circ} \mathrm{C}$ (Shaw 1977, Doorenbos \& Kassam 1979). Narciso et al. (1992) give thermal requirements for different phenological phases and different hybrid classes using a base temperature of 8 to $9^{\circ} \mathrm{C}$ (Table 1).

Table 1 Thermal time (ETS) requirement for grain maize above a base of 8 to $9^{\circ} \mathrm{C}$. (Source: Narciso et al, 1992)

\begin{tabular}{lcc} 
Hybrid class & $\begin{array}{c}\text { Sowing to flowering } \\
\left({ }^{\circ} \mathrm{C} \text { days }\right)\end{array}$ & $\begin{array}{c}\text { Sowing to ripening } \\
\left({ }^{\circ} \mathrm{C} \text { days }\right)\end{array}$ \\
\hline Early & $620-625$ & $1200-1330$ \\
Medium-late & $730-740$ & 1420 \\
Late & 795 & 1650 \\
\hline
\end{tabular}

The mapped seasonal limit for early hybrid maize $\left(1200^{\circ} \mathrm{C}\right.$ days, base $8{ }^{\circ} \mathrm{C}$ ) (Fig. $1 \mathrm{~b}$ ) is to the south of the limit based on the annual accumulation $\left(850^{\circ} \mathrm{C}\right.$ days, base $10^{\circ} \mathrm{C}$ ) (Fig. 1a). The difference amounts to approximately $380000 \mathrm{~km}^{2}$ or $4 \%$ of the land area. The current limit to production of grain maize in western Europe is in northwest Germany (Bignon 1990) and southeast England (Hough 1975). Neither the annual nor the seasonal thermal accumulation corresponds to the margin of production in Germany. However both represent the major areas of grain maize production in the EC countries (Bignon 1990). The seasonal limit is used for further analyses because it allows for evaluation of the sensitivity of different hybrid classes, and of the timing and duration of the growing season to climate change.

The expanded thermal limit for a $+2^{\circ} \mathrm{C}$ change covers all of continental Europe, the Baltic republics and much of Russia. The only areas excluded are the west of Eire, western and northern UK, almost all of Fennoscandia (with the exception of southern 
(a) Annual ETS

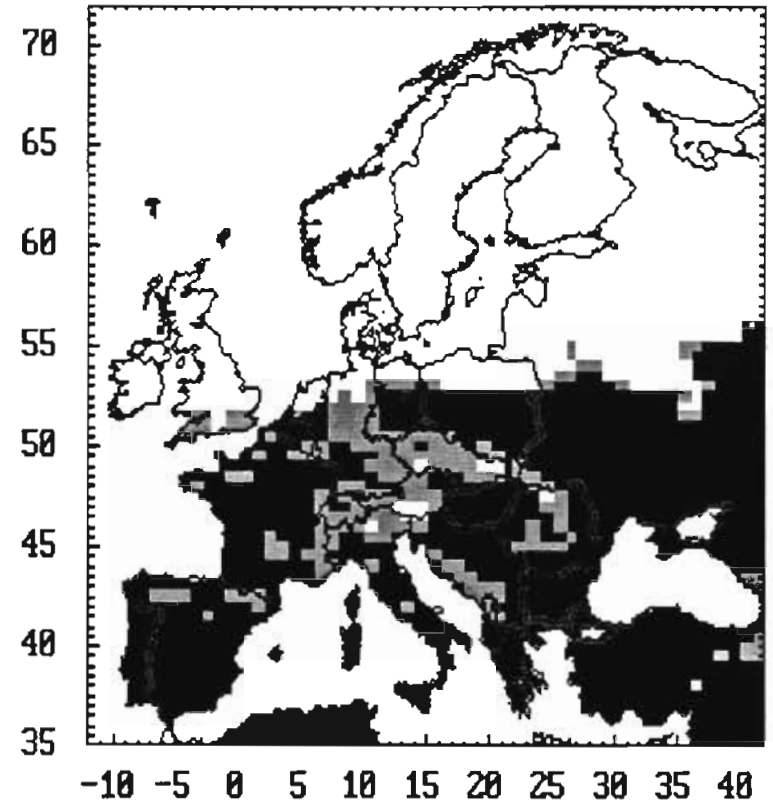

(b) Seasonal ETS

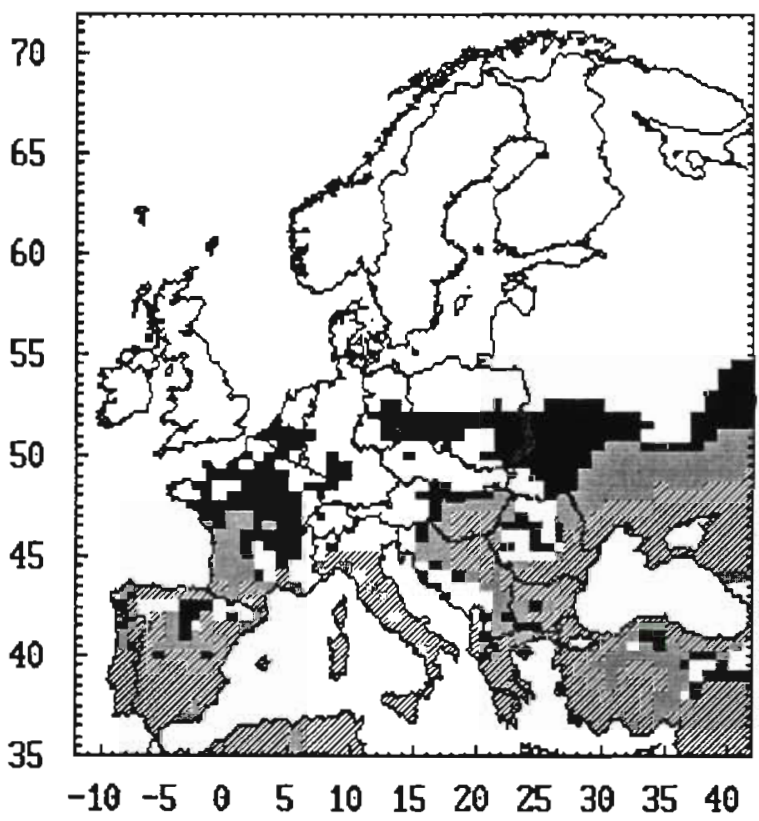

(a):

Unsuitable at all altitudes

\section{Suitable at modal} altitude

Suitable at minimum altitude (b) and (c):

Unsuitable

Early hybrids

Medium-late

hybrids

Late hybrids (c) Sensitivity test

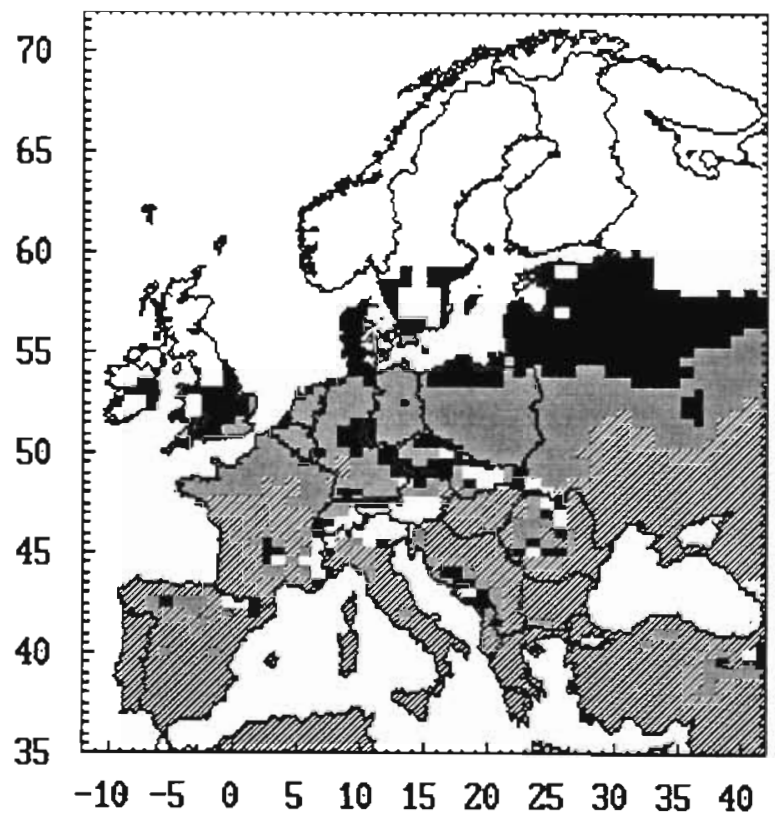

Fig. 1. Northern thermal limits of grain maize for the baseline climate (1951-1980) based on (a) an annual ETS accumulation (Carter et al. 1991), (b) a seasonal ETS accumulation (Narciso et al. 1992). (c) Sensitivity of grain maize hybrids to a $+2{ }^{\circ} \mathrm{C}$ change in temperature

Sweden) and northern Russia. This is consistent with Carter et al. (1991) who showed that an increase of only $1{ }^{\circ} \mathrm{C}$ would open up large areas of northern Europe, including southern England, the Low Countries, eastern Denmark, northern Germany and northern Poland.
A uniform temperature increase of $2{ }^{\circ} \mathrm{C}$ would lead to a significant northward shift in suitability of all 3 hybrid classes (Fig. 1c, Table 2). With such an adjustment the growing season is sufficiently warm to grow medium hybrids beyond the present margin for early hybrids. 
Table 2. Percentage area of suitability in Europe for grain maize. Note: percentage areas for hybrid classes are cumulative such that early hybrid maize covers the full area of suitability

\begin{tabular}{|lcc|}
\hline \multirow{2}{*}{ Hybrid class } & \multicolumn{2}{c|}{$\%$ Land area } \\
& Baseline climate & Baseline $+2{ }^{\circ} \mathrm{C}$ \\
\hline Unsuitable & 65.30 & 39.90 \\
Early & 34.70 & 60.10 \\
Medium-late & 24.99 & 43.72 \\
Late & 18.45 & 27.80 \\
\hline
\end{tabular}

This result does not consider the potential negative effects of a warmer climate. For example if summer conditions in southern Europe become hotter and drier there could be a contraction in the area suitable for late hybrids.

The remainder of this section considers the possible effect of temperature on the timing of key phenological events and the length of the growing season. Most analyses were made with early hybrid maize as it covers the range of commercial suitability.

\section{Effect of temperature on sowing, flowering and maturation time}

Baseline (1951 to 1980 )

A minimum temperature of $10^{\circ} \mathrm{C}$ was used to identify the earliest month suitable for sowing of grain maize across Europe. The result (Fig. 2a) shows the earliest month at the northern limit for early hybrid maize to be May. For much of southern Europe, with the exception of southern Spain, the earliest month is April. In southern Spain the earliest month is March.
These results generally concur with the earliest times of sowing for grain maize given by Bignon (1990).

The earliest months of flowering and physiological ripening were projected from the earliest month of sowing for each of the 3 hybrid classes (Table 1). The start day for the accumulation of temperatures was taken as the middle of the earliest month of sowing. The exception was the month of May, which is the sowing month in the northern zones of suitability. At the northern margins 1 May is given as the average sowing time (Bignon 1990), which was considered a more appropriate start time than mid-May.

For all 3 hybrid classes the dominant month of flowering is July, For Europe the exception is in the south, notably southern Spain and Portugal, where the earliest month for flowering is June. The result for early hybrid maize is shown in Fig. 2b. These results correspond very well with Bignon (1990) who gives July as the principal month of flowering for grain maize in Europe.

The earliest time for physiological ripening of each hybrid class generally ranged from August to October across Europe. July is the earliest possible month for early hybrid maize (Fig. 2c) in southern Spain. In all cases October is the earliest month for physiological ripening at the northern margins of production.

The length between phenological stages, and of the growing season, was calculated for early maize. These data are compared with the observed growing period length for maize (Doorenbos \& Kassam 1979) (Table 3). The predicted duration from sowing to flowering is at the upper end of the observed range. Conversely the predicted duration from flowering to physiological ripening is at the lower end of the observed range. The predicted growing season length $(124 \pm 21$ d) corresponds very closely to the observed range of growing season length (100 to $145 \mathrm{~d}$ ).

Table 3 . Sensitivity of grain maize phenology to temperature change

\begin{tabular}{|c|c|c|c|}
\hline & \multicolumn{3}{|c|}{ Duration (days) } \\
\hline & Sowing-flowering & Flowering-ripening & Sowing-ripening \\
\hline Observed range ${ }^{\circ}$ & $55-85$ & $45-60$ & $100-145$ \\
\hline \multicolumn{4}{|l|}{ Predicted (mean \pm SD) } \\
\hline Baseline (1951-80) & $75 \pm 9$ & $49 \pm 15$ & $124 \pm 21$ \\
\hline \multicolumn{4}{|l|}{ Sensitivity adjustments $\left(+2^{\circ} \mathrm{C}\right)$} \\
\hline \multicolumn{4}{|l|}{ Baseline sowing time } \\
\hline Baseline area & $64 \pm 7$ & $41 \pm 6$ & $106 \pm 12$ \\
\hline Baseline + expanded area & $69 \pm 10$ & $49 \pm 13$ & $117 \pm 22$ \\
\hline \multicolumn{4}{|l|}{ Adjusted sowing time } \\
\hline Baseline area & $74 \pm 12$ & $42 \pm 6$ & $116 \pm 15$ \\
\hline Baseline + expanded area & $75 \pm 11$ & $49 \pm 13$ & $125 \pm 20$ \\
\hline
\end{tabular}


(a) Sowing

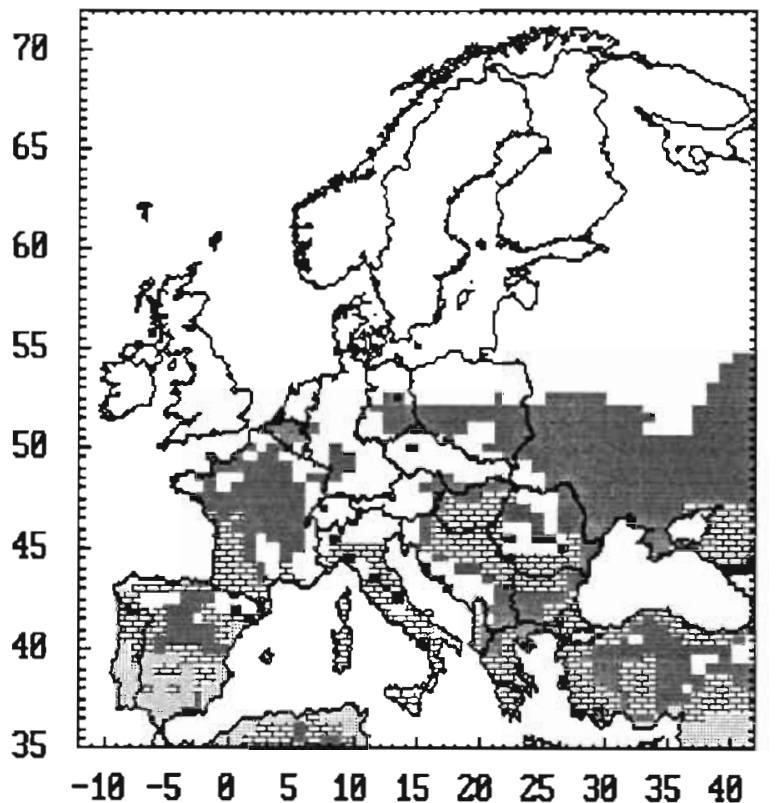

(b) Flowering

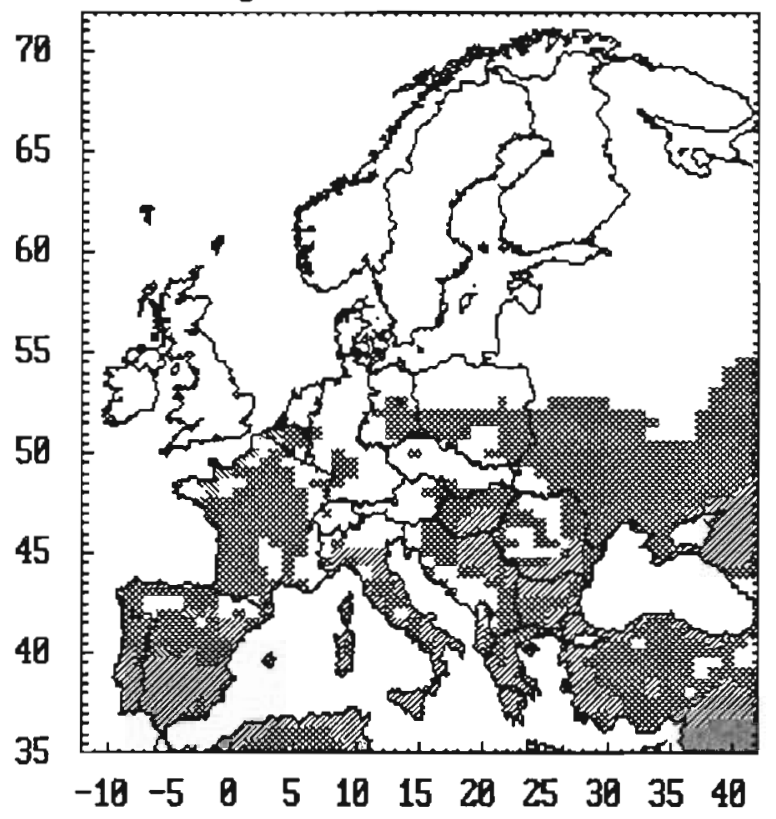

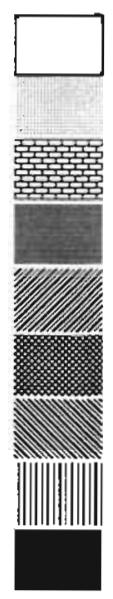

Unsuitable

March

April

May

June

July

August

September

October (c) Maturity

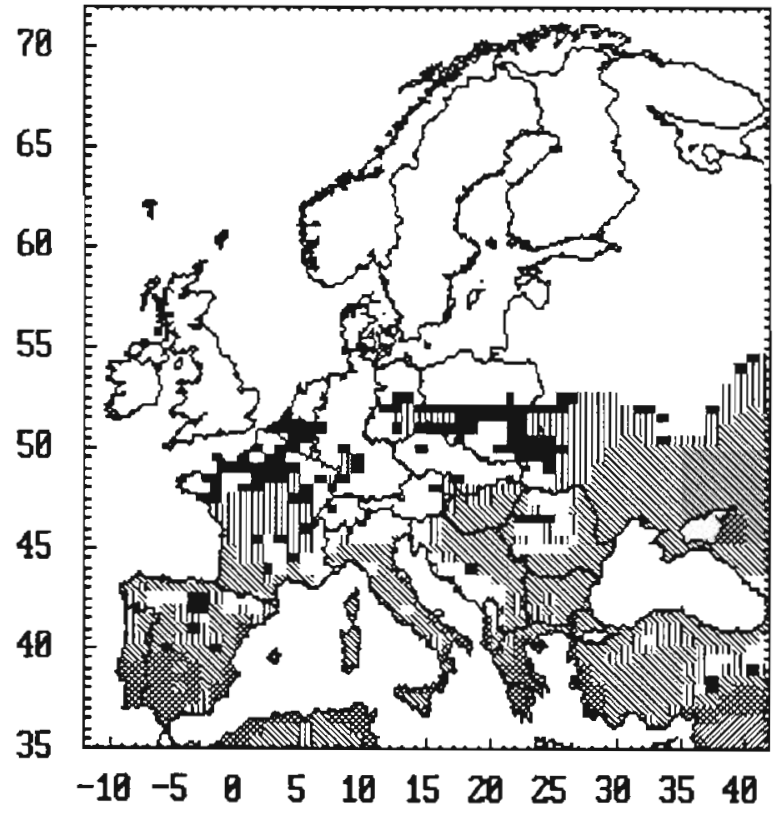

Fig. 2. Earliest month of key phenological events for early hybrid grain maize for the baseline climate (1951-1980): (a) sowing, (b) flowering and (c) physiological ripening

Sensitivity

Sensitivity experiments were carried out on the month of sowing by making stepwise adjustments to temperature from -1 to $+4^{\circ} \mathrm{C}$. Results show that a temperature change of $+2{ }^{\circ} \mathrm{C}$ generally shifts the time of sowing forward by a month (Fig. 3a). Exceptions are in southern Spain, parts of Italy and the Balkan region, where the shift is less than a month. Consistent with this result, the dominant month of flowering becomes June under a $2^{\circ} \mathrm{C}$ temperature increase (Fig. 3b). Similarly the time of physiological 
(a) Sowing

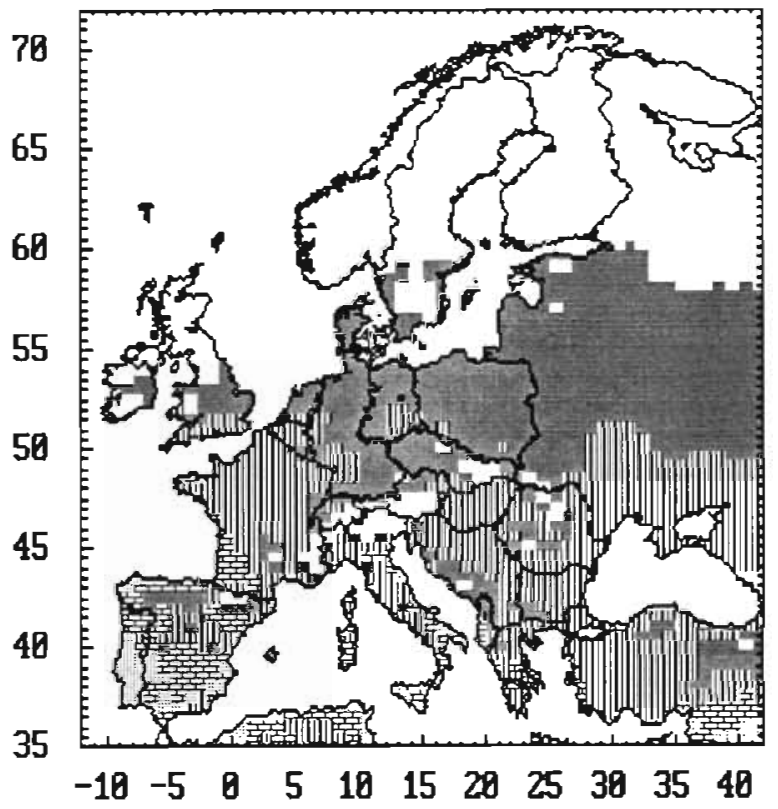

\begin{tabular}{|l|l}
\hline & Unsuitable \\
February
\end{tabular}

(c) Maturity

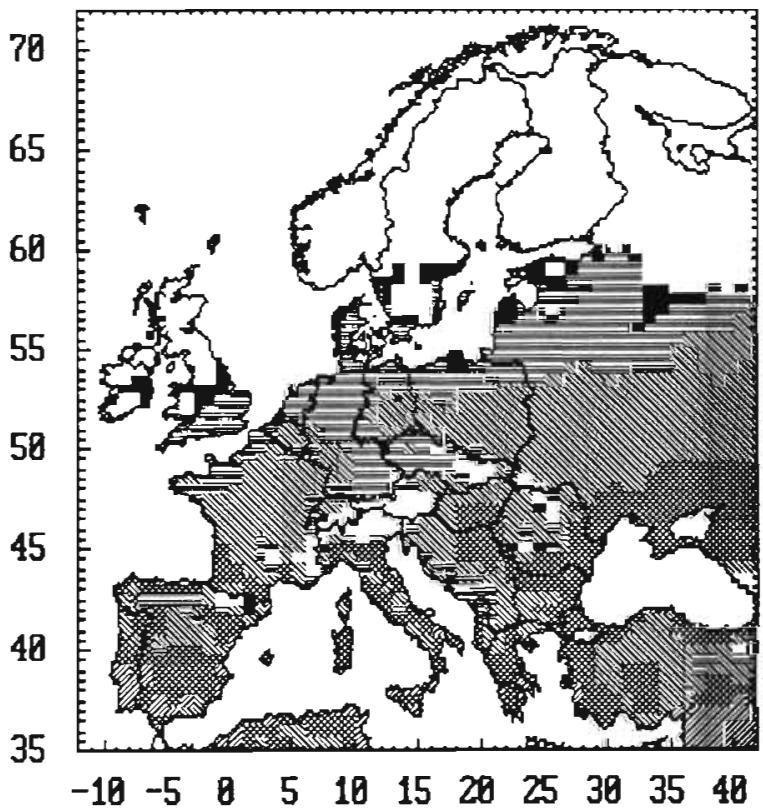

Fig. 3. Sensitivity of the earliest month of key phenological events to a $+2{ }^{\circ} \mathrm{C}$ temperature change for early hybrid grain maize (a) sowing, (b) flowering and (c) physiological ripening

ripening moves forward by a month over most areas (Fig. 3c).

The effect of a $2{ }^{\circ} \mathrm{C}$ temperature increase on the duration between phases and on the growing season length was calculated (Table 3). The analyses included an adjustment to the timing of sowing under the warmer temperature regime. If the sowing time is not changed there is a clear shortening of the growing season, as well as a reduction in the spatial variability (as indicated by the relatively low standard deviation, $\pm 12 \mathrm{~d}$ ) of the growing season length. When the area of expanded suitability is considered the net result is still 
a shortening of the length of the growing season, but to a much lesser degree. This result is weighted by the expanded northern limit, where there is a longer (cooler) growing season. If the sowing time is adjusted forward the growing season is cooler than if it were not adjusted. This minimises the effect of warmer temperatures on shortening the length of the growing season. The mean and standard deviation of the duration between all phases is the same as for baseline conditions over the entire area of suitability for the adjusted sowing time.

These results have important implications. If adjustments are not made to the timing of sowing under a warmer climate then cultivars that are more suitable for a shorter growing season may have to be introduced. Present cultivars could be retained if the start of the growing season is shifted forward, and in areas of expanded suitability. Sowing earlier may not be feasible in areas where an annual crop rotation is practised. Another crucial climatic factor that may determine the timing of sowing is the effect of climate change on the availability of moisture for crop growth.

\section{MOISTURE LIMITS TO GROWTH}

\section{Precipitation requirements}

Globally, maize is grown in an annual precipitation range from as low as $250 \mathrm{~mm}$ to higher than $5000 \mathrm{~mm}$ (Shaw 1977). The minimum summer (June, July, August) precipitation requirement for rainfed grain maize is approximately $150 \mathrm{~mm}$ but irrigation above this level can increase yields (Shaw 1977). Bignon (1990) indicates that there are minimal benefits from irrigation in Europe where the summer precipitation is more than $250 \mathrm{~mm}$.

These are general thresholds that will vary between sites and years according to the intensity and timing of precipitation. For rainfed crops the amount of precipitation and its timing in relation to crop development is critical to yield (Carr \& Hough 1978). Soil water holding capacity is also very important. In low rainfall countries, such as Botswana, farmers tend to grow maize on soils with a higher moisture holding capacity (Vossen 1989). This is also generally true of Europe, although wide use of irrigation enables the crop to be grown on coarser soils. The disadvantage of using water-retentive soils at the northern, thermal margins of production is that the soil will warm more slowly in the spring and delay establishment of the crop (Carr \& Hough 1978).

Flowering is the most moisture sensitive phase of development for maize (Doorenbos \& Kassam 1979). Despite wide variations in the timing and length of the growing season in Europe, Bignon (1990) confirms that flowering of the maize crop occurs, almost universally, in July. Therefore summer (June, July, August) precipitation may provide a reasonable indicator of suitability for rainfed grain maize production in Europe.

Precipitation thresholds were used to map the suitability of rainfed grain maize in Europe. As temperature is the main determinant of whether the crop will develop to maturity the thermal constraint for early hybrid maize $\left(1200^{\circ} \mathrm{C}\right.$ days, base $\left.8^{\circ} \mathrm{C}\right)$ was imposed. Within the thermal limit 3 classes of suitability, corresponding to the precipitation thresholds, were identified:

(0) Thermally unsuited (less than $1200^{\circ} \mathrm{C}$ days, base $8{ }^{\circ} \mathrm{C}$, May to October).

(1) Irrigation essential, where summer precipitation is less than $150 \mathrm{~mm}$.

(2) Irrigation benefits, where summer precipitation is between 150 and $250 \mathrm{~mm}$.

(3) Un-irrigated, where summer precipitation is greater than $250 \mathrm{~mm}$.

Summer precipitation is sub-optimal over most of the area of thermal suitability in Europe (Fig. 4a). Conditions are most water-limited in Spain, southern Italy and southern Greece. Areas where summer precipitation is greater than $250 \mathrm{~mm}$ are confined to the margins of high altitude zones.

\section{A crop-specific water balance}

The precipitation thresholds are based on experience and observation for recent conditions, and may not fully account for possible future conditions. If the climate of the future is warmer than the present this could lead to higher levels of water use by maize through increased evapotranspiration. An annual increase in potential evapotranspiration (PET) of the order of 55 to $70 \mathrm{~mm}$ for each $1^{\circ} \mathrm{C}$ rise in annual temperature has been estimated for the southern Mediterranean (Le Houerou 1990). A similar order of magnitude of change is indicated by Rowntree (1990), who estimates an increase of $50 \mathrm{~mm}$ per $1{ }^{\circ} \mathrm{C}$ temperature increase over a 6 month growing season in midlatitudes. A verification of these 2 values was made using the temperature based Thornthwaite method to calculate PET. From this the mean annual change across the whole of Europe is of the order of $32 \mathrm{~mm}$. However the range is considerable, from $7 \mathrm{~mm}$ up to $70 \mathrm{~mm}$. In southern Europe, south of $40^{\circ} \mathrm{N}$, the range is from 30 to $70 \mathrm{~mm}$, with a mean value of $49 \mathrm{~mm}$. This is consistent with estimates by Le Houerou (1990). Assuming no change in precipitation this could have a significant impact on agriculture in the low rainfall 
(a) Precipitation Limits

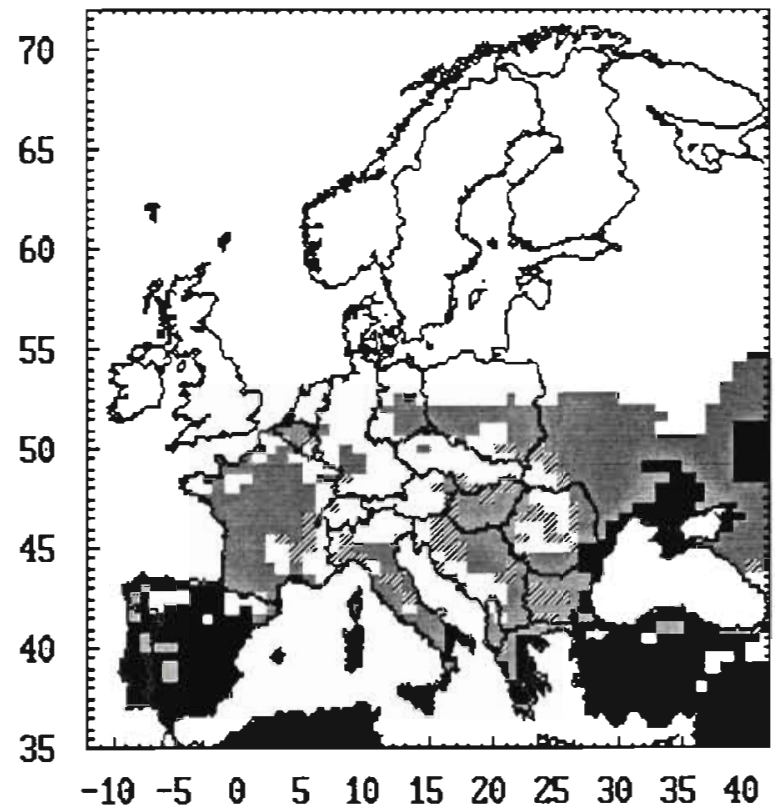

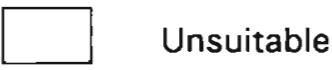
$\begin{array}{ll}\text { HIIIIIIIIII. } & \text { Suitable with no } \\ \text { irrigation requirements }\end{array}$

Yield benefits with irrigation

Irrigation essential for maize production

(b) Water Balance

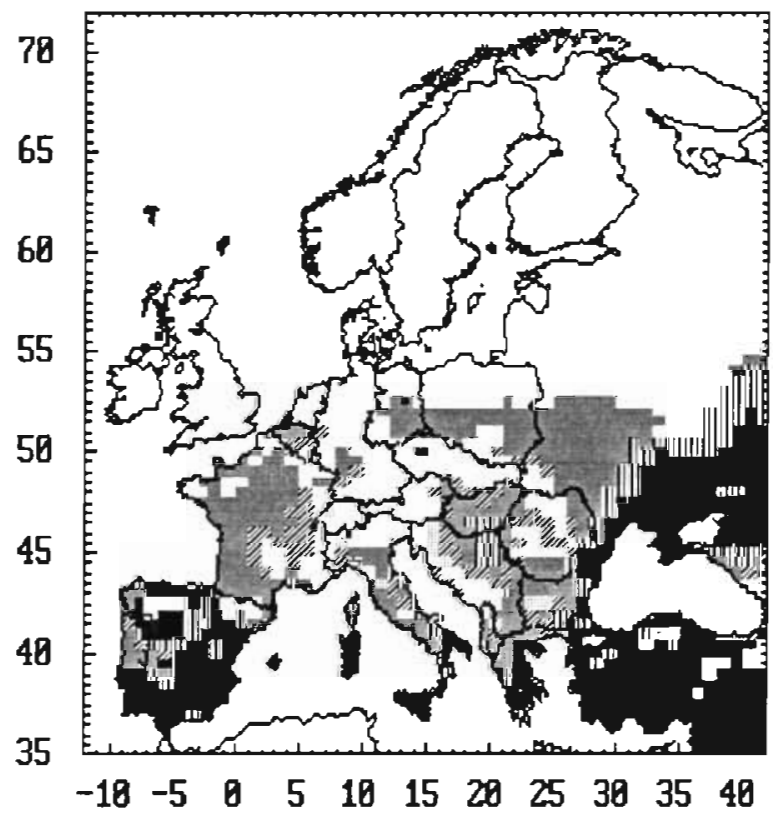

Unsuitable

Very good

Good

Average

Mediocre

Poor

Crop failure

Fig. 4. Water constraints to grain maize suitability within the seasonal thermal limit for the baseline climate (1951-1980): (a) summer (June, July, August) precipitation and (b) the water requirement satisfaction index (WRSI)

areas of Europe under a warmer climate, in particular the Mediterranean. The possible negative effects of increased PET on the water available to a maize crop must be balanced against possible improved water use efficiency from increased levels of atmospheric $\mathrm{CO}_{2}$. However, the response of maize (a $\mathrm{C} 4$ plant) to increased atmospheric $\mathrm{CO}_{2}$ has not been well quantified, but is likely to be less than that of $\mathrm{C} 3$ crops such as soybean and wheat (Parry et al. 1990). Such effects were not considered in this study.

A simple water balance model was used to evaluate the effect of temperature induced changes in PET on 
the water available to grain maize. While a simple atmospheric water balance (precipitation-PET) could have been used, it would not have been possible to directly relate the output from this to a specific crop. It was therefore decided to use a crop-specific water balance (FAO 1986). Within this model PET is adjusted according to the crop demand for water over a particular development stage, using a crop coefficient $(\mathrm{Kcr})$ to give the crop water requirements $(W)$. The crop coefficients are derived from the ratio between maximum crop evapotranspiration $\left(E T_{m}\right)$ and the reference evapotranspiration ( $\mathrm{ET}_{0}$ ) (Doorenbos \& Kassam 1979). The difference between precipitation and available soil water is calculated for successive development phases to determine whether the soil is in deficit or surplus. The accumulated difference between crop water requirement and deficit is expressed as a ratio of the total crop water requirement. This is referred to as the water requirement satisfaction index (I) (FAO 1986) and is expressed in Vossen (1989) as:

$$
I=\left\lfloor\sum_{i=1}^{n}\left(\mathrm{~W}_{i}-\text { deficit }\right) / \sum_{i=1}^{n} \mathrm{~W}_{i}\right\rfloor \times 100
$$

where $W_{i}$ is the water requirement of the crop in a given month, $i$; and $n$ is the total number of months covering the growing season.

For the purposes of this paper the water requirement satisfaction index is subsequently referred to as WRSI.

The analyses of the growing season for grain maize in Europe show wide spatial variation in timing and duration of crop development. However, as these are based on the earliest month of sowing they do not capture the temporal variability that results from a range of sowing times. By considering the range of sowing times by country and across Europe the average growing season for grain maize generally extends from May to October, with July being the month in which flowering most commonly occurs (Bignon 1990). This average season was used for development and testing of the water balance model. Dekadal (10 d) crop coefficients for grain maize (FAO 1986) were extrapolated to this average European growing season and averaged to give monthly values (Table 4 ).

The mid-season value of 1.2 is at the top of the range (1.05 to 1.2 ) given by Doorenbos \& Kassam (1979), and applies to hot, dry conditions. This tends to represent a more extreme case when applied uni-

Table 4. Crop coefficients ( $\mathrm{Kcr}$ ) for grain maize in Europe (for the average growing season)

\begin{tabular}{|ccccccc|}
\hline & May & Jun & Jul & Aug & Sep & Oct \\
\hline Kcr & 0.5 & 0.9 & 1.2 & 1.0 & 0.8 & 0.5 \\
\hline
\end{tabular}

versally across Europe. In subsequent analyses variations in these coefficients were made to account for the spatial variability of the growing season and for the climatic differences between arid (higher $K \mathrm{cr}$ values) and cooler, temperate (lower $\mathrm{Kcr}$ values) parts of Europe.

The likely performance of grain maize under rainfed conditions was assessed for those areas within the thermal limit for early maize $\left(1200^{\circ} \mathrm{C}\right.$ days, base $\left.8^{\circ} \mathrm{C}\right)$. Classification of crop performance was based on that provided by the FAO (1986) (Table 5).

Table 5. Classification of the water requirement satisfaction index (WRSI) (source: FAO 1986)

\begin{tabular}{|llc|}
\hline $\begin{array}{l}\% \text { of yield in } \\
\text { relation to average } \\
\text { of } 3 \text { best yields }\end{array}$ & $\begin{array}{l}\text { Crop } \\
\text { performance }\end{array}$ & Index (I) \\
\hline$>100 \%$ & Very good & 100 \\
$90-100 \%$ & Good & $95-99$ \\
$50-90 \%$ & Average & $80-94$ \\
$20-50 \%$ & Mediocre & $60-79$ \\
$10-20 \%$ & Poor & $50-59$ \\
$<10 \%$ & Crop failure & $<50$ \\
\hline
\end{tabular}

\section{Comparison of moisture indices}

Visual comparison of the precipitation limits with the water balance output (Fig. 4a, b) suggests a high degree of correspondence between the two. This is verified by producing a scatter plot of the data (Fig. 5). The fitted regression line demonstrates a significant relationship $\left(\mathrm{R}^{2}=92.4 \%, \mathrm{p}<0.01\right)$ between the two. In addition the thresholds for irrigation are closely related (precipitation $\leq 150 \mathrm{~mm} \approx$ WRSI $\leq 50$ ). Similarly there is a very good correspondence between the upper thresholds beyond which there are minimal benefits from irrigation (precipitation $\geq 250 \mathrm{~mm} \approx$ WRSI $\geq 80$ ). Index values greater than 80 would most likely be influenced predominantly by the timing of precipitation rather than the quantity.

Further validation was made by comparing the maps with available information on the extent of irrigated maize in the EC (Bignon 1990). In virtually all areas of Spain and Greece, $100 \%$ of the crop is irrigated. This corresponds with those areas indicated as crop failure in Fig. 4b. No data were available for Italy. In France there is generally more irrigation in the west and south (up to $70 \%$ of the acreage in the south) and less in the east (as little as $5 \%$ of the acreage). This corresponds with mediocre and average crop performance respectively (Fig. 4b). 


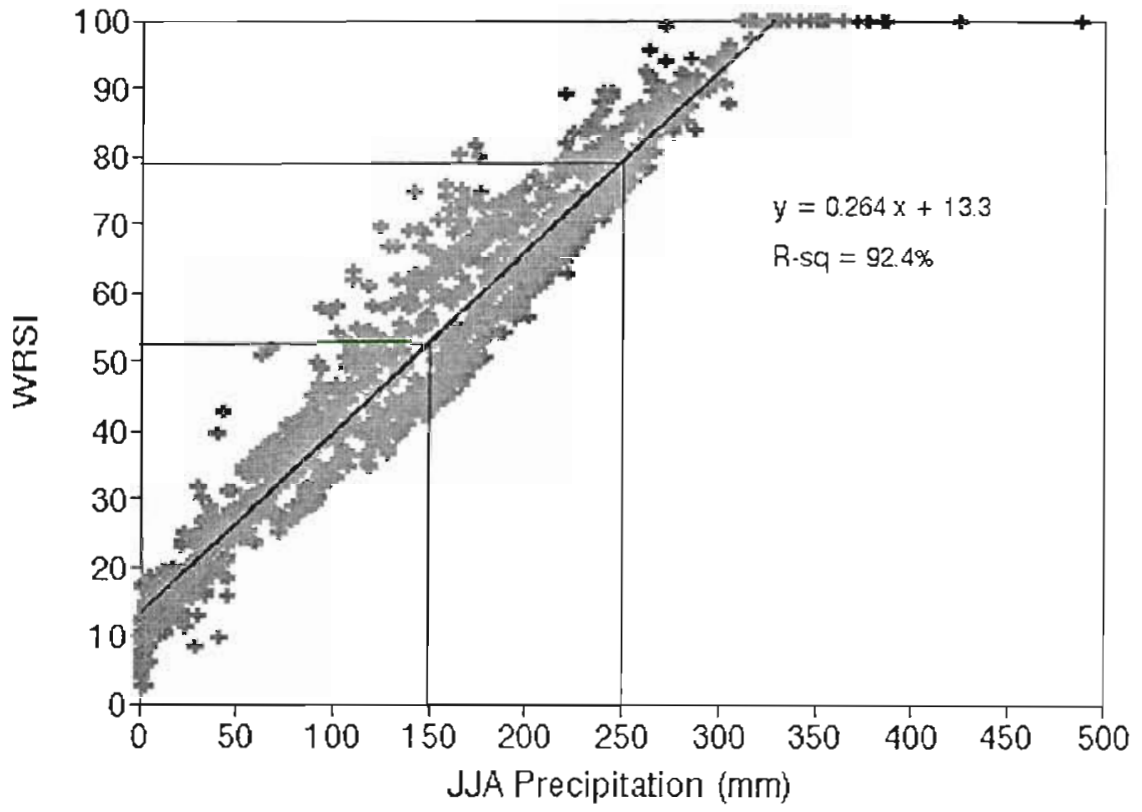

Fig. 5. Comparison of grain maize moisture indices for the baseline climate (1951-1980)
A question that stems from this result is, why not use precipitation as an index of crop water availability rather than the water balance? The former would be far simpler to apply as an agroclimatic index. This may be satisfactory under present climatic conditions. However under a warmer climate, use of the water balance model allows for consideration of the combined effects of changes in PET and precipitation which is not possible by using precipitation alone. A sensitivity analysis showed that an approximate $10 \%$ increase in precipitation would be required to offset the negative effects of a $2{ }^{\circ} \mathrm{C}$ temperature increase on PET. If average climatic conditions change in the future then obviously new precipitation thresholds would need to be defined. This confirms the view that precipitation is not a satisfactory indicator of water requirements for assessing the impact of climate change on a specific crop. The sensitivity of the water balance to changes in PET (as a result of temperature change) is evaluated in more detail in a later section. The uncertainty within the Thornthwaite method for calculating PET is considered first.

\section{EVALUATION OF UNCERTAINTY WITH PET ESTIMATES}

In arid environments the Thornthwaite method for calculating potential evapotranspiration (PET) performs poorly when compared to other methods (Jensen et al. 1989). It performs better in humid environments, for which it was originally developed. As a key input to the water balance it was considered essential to evalu- ate the uncertainty that may arise from using this method for PET calculation in Europe.

A comparison was made between output from the Thornthwaite and Penman methods of PET calculation. Penman PET data were available from the FAO agrometeorological database (FAOCLIM). These were calculated according to the FAO-24 method (Doorenbos \& Kassam 1979, FAO 1986). This method performed similarly to the Thornthwaite method in humid environments, but ranked higher in arid environments (Jensen et al. 1989). Analysis was restricted to latitudes south of approximately $50^{\circ} \mathrm{N}$ (no FAO data were available for higher latitudes), and to sites that matched those from which monthly temperatures were interpolated for Europe (Carter et al. 1991). Countries included in the comparison were France, Italy, Spain, Greece and the former Yugoslavia.

A scatter plot of output from the 2 methods showed no consistent relationship. Ratios were calculated between the two for each month of the average (May to October) growing season, for each site. They were averaged by country and then averaged over all countries used in the analysis (Table 6).

Table 6. Ratios of Penman/Thornthwaite PET (sites south of $\left.50^{\circ} \mathrm{N}\right)$

\begin{tabular}{lcccccc|}
\hline & May & Jun & Jul & Aug & Sep & Oct \\
\hline Average & 1.2 & 1.1 & 1.0 & 1.0 & 1.0 & 0.9 \\
High & 1.3 & 1.2 & 1.1 & 1.1 & 1.1 & 1.0 \\
Low & 1.1 & 1.0 & 0.9 & 0.9 & 0.9 & 0.8 \\
\hline
\end{tabular}


Several patterns emerged from this approach:

(1) There is a gradient from overestimation (by the Thornthwaite method relative to the Penman method) to underestimation across the average (May to October) growing season.

(2) In France and Italy there are distinct latitudinal gradients, with overestimation by the Thornthwaite method in northern latitudes (from approximately 44 to $50^{\circ} \mathrm{N}$ ) and underestimation in the south.

(3) In Spain, with few exceptions, the Thornthwaite method consistently underestimates PET relative to the Penman method.

The first pattern appears to be related to the monthly latitude adjustment factors that are incorporated into the Thornthwaite calculation. If it is assumed that the Penman method is the more accurate (which is true for the more arid southern latitudes) then this result suggests that the adjustment factors have not been sufficiently well calibrated for Europe. It is less clear whether the latitudinal differences are related to these adjustment factors, or reflect other computational differences.

In order to quantify the effect of these differences on the water balance output, a series of sensitivity experiments were carried out. This involved adjusting Thornthwaite PET by the average, high and low ratios (Table 6). Uniform adjustments in PET of $\pm 10 \%$ to each month were also made. From the range of ratios only the high adjustment gave a significant change in the water balance. As a general rule it was found that significant changes in the water balance occur with a change in PET of the order of $\pm 10 \%$. It is recalled that the tendency is for overestimation of Thornthwaite PET in the north (up to $50^{\circ} \mathrm{N}$ ) and underestimation in the south, most notably in Spain. The effect of making a $10 \%$ downward adjustment in the north is to shift the water balance classification from mediocre to average in parts of western France and southern Germany. In Spain with an upward adjustment in PET of $10 \%$ some areas are reclassified from poor to failure for rainfed conditions.

It can be concluded that there are important differences in the methods of calculating PET. These are borne in mind in the subsequent sensitivity analyses. It must also be emphasised that because the Thornthwaite method is empirical, and calibrated for present conditions, it is likely that it will have to be geographically re-calibrated if mean changes in the climate do in fact occur in the future. Essentially this would require re-evaluation of the latitude adjustment factors.

\section{CLIMATE SENSITIVITY OF THE WATER BALANCE (AVERAGE GROWING SEASON)}

\author{
Sensitivity to changes in temperature
}

Stepwise adjustments of $1^{\circ} \mathrm{C}$ were made to the temperature data over the range +1 to $+4{ }^{\circ} \mathrm{C}$. Thornthwaite PET was recalculated with these data, and the water balance rerun for the average growing season. No significant change in the mean WRSI resulted for a $1^{\circ} \mathrm{C}$ increase in temperature. However there was a highly significant $(p<0.01)$ difference in the mean for $\mathrm{a}+2{ }^{\circ} \mathrm{C}$ change in temperature from the baseline.

\section{Sensitivity to changes in temperature and precipitation}

Adjustments to both temperature and precipitation showed that by increasing temperature by $2{ }^{\circ} \mathrm{C}$ and increasing precipitation by $10 \%$ there was no significant change in the WRSI. Only $3 \%$ of the gridded data changed an index class. In general, analyses show that the effect of changing precipitation by $10 \%$ has the same magnitude of effect (but opposing) on the WRSI as changing temperature by $2{ }^{\circ} \mathrm{C}$.

The percentage change in index values for $\mathrm{a}+2{ }^{\circ} \mathrm{C}$ sensitivity adjustment does not vary greatly with latitude and is of the order of $7 \%$ on average. It is the absolute change that tends to have the most critical effect. South of approximately $40^{\circ} \mathrm{N}$ the absolute change is minimal, as is its effect on the classification of the output. Index values are mostly below 50 in this latitudinal range which corresponds to the lowest FAO classification of crop failure (FAO 1986). The increasingly water-limited conditions resulting from increased temperatures and/or decreased precipitation are therefore not apparent in the mapped output at lower latitudes where crop failure is already indicated for baseline conditions. Where index values are higher, which is generally at higher latitudes, the range assigned to a class is narrower than for lower values (FAO 1986). Given that the absolute change is also greater at higher latitudes, class changes in the water balance are therefore most likely to occur in these regions, particularly where a value is already marginal between 2 classes. This interpretation concurs with assessment of the mapped output which shows mid-latitude areas to be more sensitive to class changes than southern Europe, where conditions become more water limited, but remain in the crop failure class.

When the uncertainty with PET is incorporated in the analyses, a similar pattern emerges. The mid-latitudes, in particular France, parts of southern Germany and the Ukraine, are the areas most sensitive to changes in PET. 


\section{MAPPING LIMITS TO PRODUCTION USING A VARIABLE GROWING SEASON}

It is unrealistic to assume the same growing season across Europe, other than for model validation and sensitivity evaluation. As has been shown, the growing season for early hybrid grain maize is highly variable. The water balance was recalculated for the baseline climate, incorporating the spatial variability in the growing season. For early hybrid maize 6 dominant combinations of sowing, flowering and physiological ripening time were identified. Regional adjustments were made to the crop coefficients for each of these combinations. The upper limit of the range for the coefficients was used in hotter, drier regions and the lower limit in the cooler, temperate regions as recommended by Doorenbos \& Kassam (1979).

Output for the fixed and variable growing season compare well (Figs. $4 \mathrm{~b} \& 6$ ). The main differences are a $3 \%$ reduction in the area classed as crop failure and a $1.5 \%$ increase in the area classed as average. Southwest France and northern Portugal are reclassified to average performance. Similar changes can be seen in parts of Italy. However crop performance remains poor over much of Spain, and generally low over much of the present area of suitability for grain maize.

\section{CLIMATE SENSITIVITY OF THE WATER BALANCE (VARIABLE GROWING SEASON)}

While farmers can be regarded as risk takers they will adopt strategies to minimise risk where they can

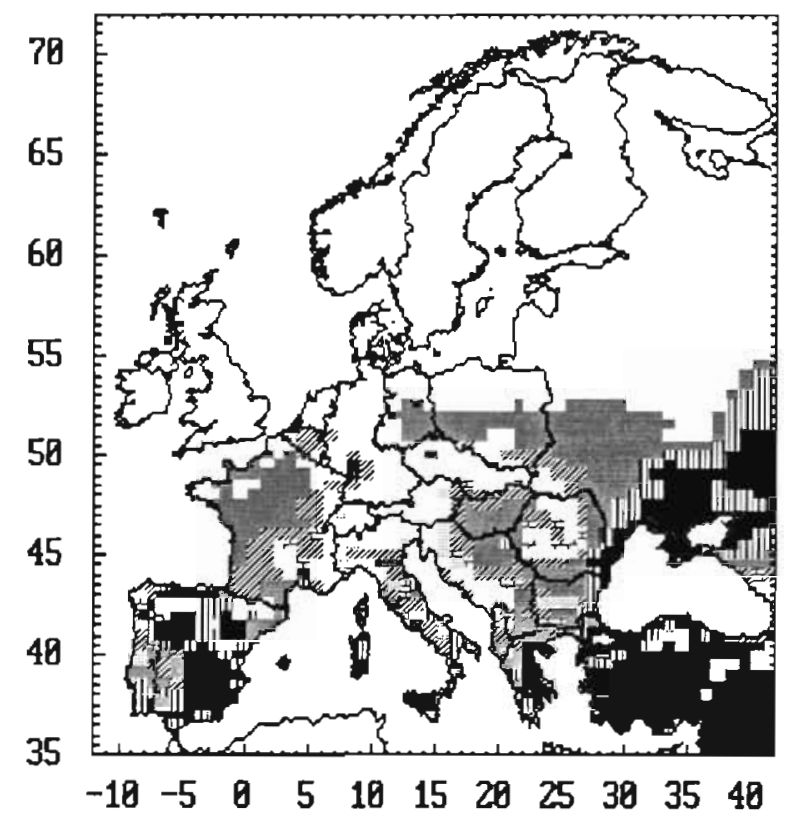

see an economic benefit. If it becomes unequivocal that climate is changing then farmers will adapt to changing conditions, where there are perceivable benefits. Options that a farmer may consider would include sowing earlier and shifting to new cultivars. With this in mind an array of experiments were carried out to evaluate the sensitivity of the water balance model to changes in the timing of sowing and growing season length (which could lead to a change in cultivar) under a warmer (and wetter/drier) climate.

The sensitivity adjustments to the climate data included $+2{ }^{\circ} \mathrm{C}$ and $\pm 10 \%$ precipitation. These were combined with an evaluation of the effect of changing the timing of sowing. Sowing time was kept fixed at the baseline, and adjusted for a $2{ }^{\circ} \mathrm{C}$ warmer climate. Times of flowering and physiological ripening were projected from the fixed and adjusted sowing times (summarised in Table 3 ) and the water balance rerun for the array of climate adjustments. There was no adjustment to sowing time in the areas of expanded thermal suitability. It was assumed that in these areas sowing would take place at the earliest possible time because of the relatively cool growing season. The growing season combinations were therefore identical in these areas for all of the sensitivity analyses.

\section{Sensitivity to changes in temperature}

If sowing time is not changed under a warmer climate $\left(+2^{\circ} \mathrm{C}\right)$ the growing season for early maize becomes shorter (Table 3 ). This has a net negative

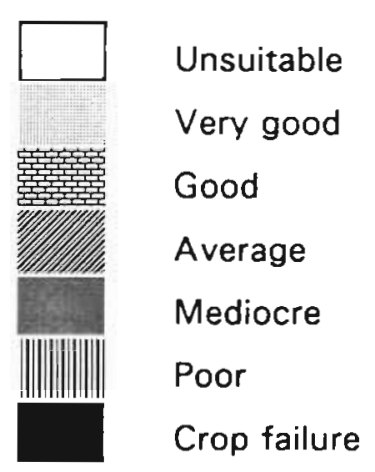

Fig. 6. Combined thermal and moisture limits for early hybrid grain maize under a spatially variable growing season $(1951-1980)$ 
effect (Fig. 7a) on the water balance resulting from increased PET due to increased temperatures. However the effect is not as negative as it might be if the growing season remained the same length as the present (this would imply the use of a later maturing cultivar). With a shortened growing season there is a lower accumulated deficit and therefore relatively higher index values. The result would be further compounded if the effect of temperature on growth was incorporated. For the same cultivar a shortened growing season could lead to reduced accumulation of dry matter and lower yields. This result suggests that if sowing time is not changed the best adaptation strategy could be to shift to cultivars that are best adapted to a shorter growing period.

There is a clear net benefit from adjusting the timing of sowing (Fig. $7 b$ ) for $+2{ }^{\circ} \mathrm{C}$ with a notably greater amount of scatter above the 1:1 line than below. Closer analysis of the data reveals that there are 2 groups of response. WRSI values generally increase in areas south of a latitude of approximately $44^{\circ} \mathrm{N}$, while there is a slight negative response for areas north of $44^{\circ} \mathrm{N}$. This difference in response is possibly related to the time of the year to which the growing season is moved. In the south an earlier sowing time means that the growing season no longer extends over the full summer period and the growing season is cooler than if sowing time were not adjusted. This offsets the otherwise negative effect of increased PET. In the north the growing season is earlier, but remains centred on mid-summer leading to no net change. An advantage to sowing earlier is that the growing season does not shorten as much (Table 3). This would give greater flexibility in choice of cultivars. As mentioned previously, sowing earlier may not be such a desirable option where an annual crop rotation is currently practised. (a) Unadjusted sowing date

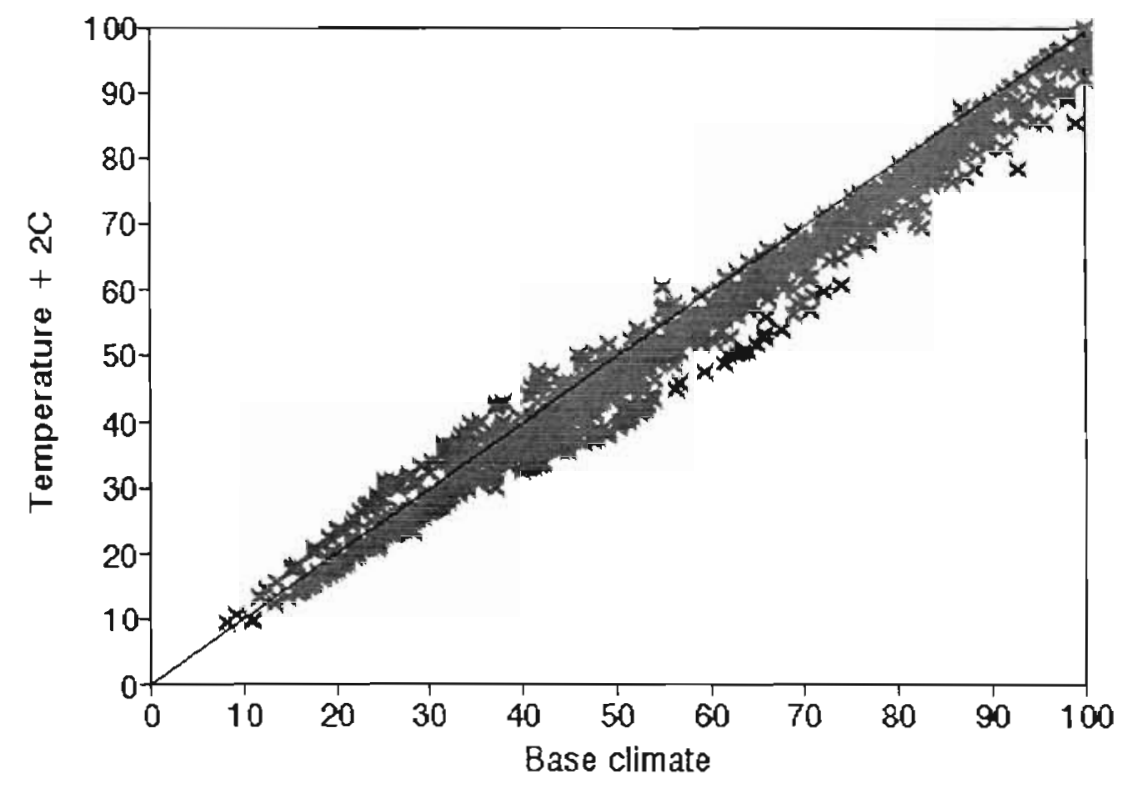

(b) Adjusted sowing date

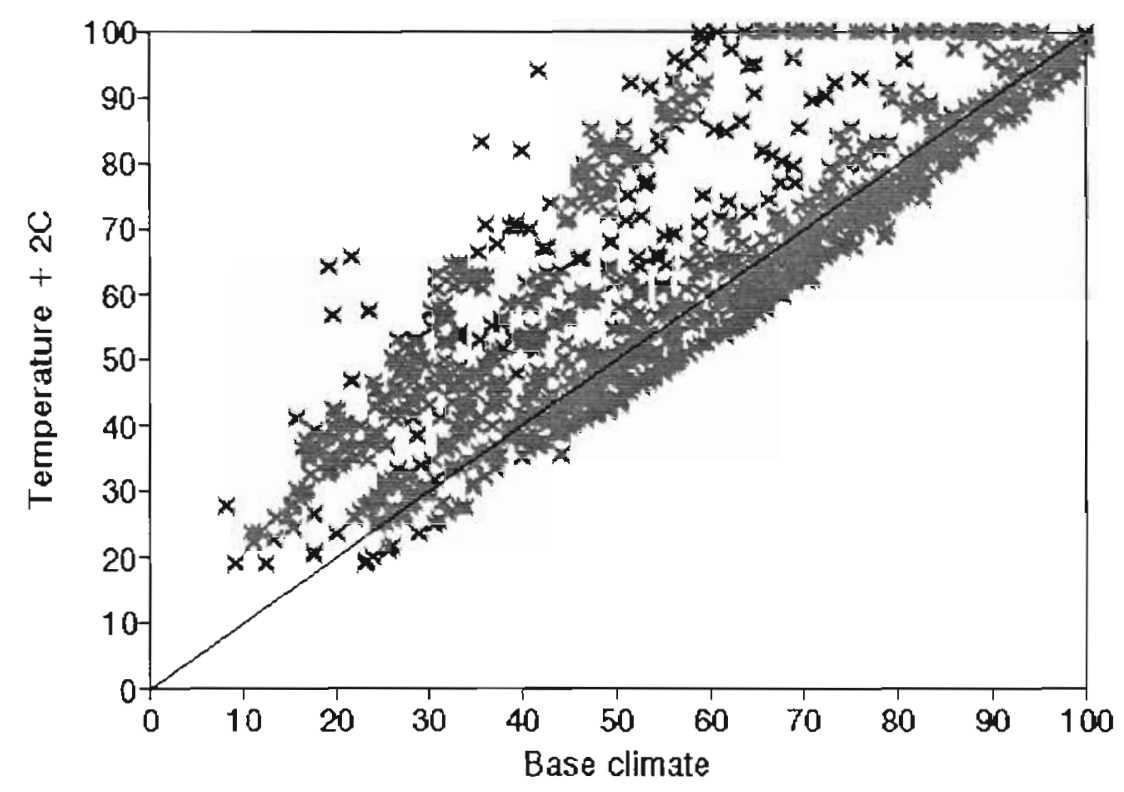

Fig. 7. Change in WRSI for grain maize based on a $2^{\circ} \mathrm{C}$ temperature increase with (a) no adjustment to sowing time and (b) adjustment to earliest possible sowing time
In the area of expanded thermal suitability (Table 1) approximately $60 \%$ of WRSI values are classified as mediocre if there is no change in precipitation. As these areas would be the new margins of suitability there would be a limited choice of management options open to a farmer. With a relatively cool growing 
Grain maize: Sensitivity Analyses

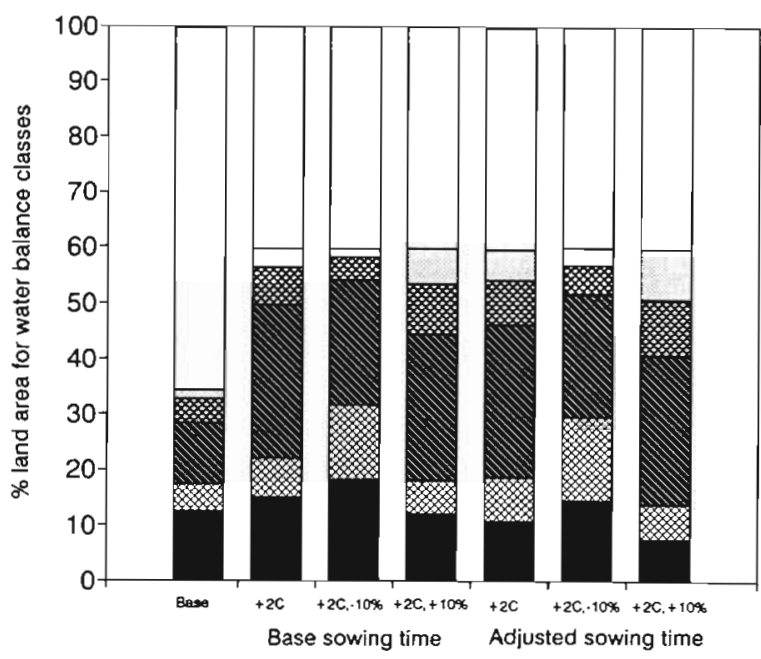

Fig. 8. Percentage land area covered by the WRSI classes for the array of sensitivity analyses

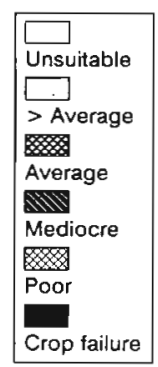

season the viability of grain maize may be restricted to those areas with adequate rainfall and/or an available supply of water for irrigation.

\section{Sensitivity to changes in temperature and precipitation}

Of the array of sensitivity analyses a decrease in precipitation $(-10 \%)$, in combination with a $2{ }^{\circ} \mathrm{C}$ temperature increase and no adjustment to the sowing time, presents the most water-limited situation (Fig. 8). Close to $30 \%$ of the area of suitability shows crop failure. If there is an increase in precipitation for $+2{ }^{\circ} \mathrm{C}$ warming and no change in sowing time, the situation is similar to the present. The greatest benefit to the maize crop occurs under a warmer climate, if the sowing time is adjusted and precipitation increases. It is possible for a farmer to manage the timing of sowing, and potentially realise benefits from such a strategy. However there is always likely to be uncertainty over long-term (and interannual) variations in precipitation. This uncertainty (for altered mean conditions) is demonstrated in the results (Fig. 8 ).

Of the areas of expanded thermal suitability, the principal countries to benefit if precipitation is increased uniformly by $10 \%$ are Germany and the west of the UK (Fig. 9b). However, much of the area of expanded potential would be water-limited for grain maize. The only areas to show at least average crop performance for a reduction in precipitation (Fig. 9a) are largely restricted to the margins of mountainous zones.

The comparison of Thornthwaite PET with Penman PET showed that the former tends to underestimate in southern Europe and overestimate at the present northern limit (from 44 to $50^{\circ} \mathrm{N}$ ). This adds uncertainty to the water balance output, in particular at the northern margins where it was shown the water balance is most sensitive to changes in PET. In the south it is evident that while there may be uncertainty about the degree of water limitation, conditions remain waterlimited, both when the uncertainty with PET is considered and under the different sensitivity adjustments.

Despite the uncertainties, it is clear that even for the most positive situation $\left(+2{ }^{\circ} \mathrm{C},+10 \%\right.$ precipitation, adjusted sowing time) there are large areas of Europe that show below average crop performance. It is useful to take the present situation in France as an indicator. Areas in this country that show below average crop performance from the water balance correspond with areas that are as much as 50 to $70 \%$ irrigated at present (Bignon 1990). This would suggest that a large proportion of the area of expanded thermal suitability, for both $\pm 10 \%$ changes in precipitation, would require some irrigation input to sustain a satisfactory level of crop performance. It is evident that the availability of water will be critical to determining those regions of both present and expanded thermal suitability that are viable for the growing of grain maize under a warmer climate.

\section{SUMMARY AND CONCLUSIONS}

It was suggested in the introduction that the climatic limits to grain maize in Europe are temperature at the northern margins and availability of water in southern Europe. The preceding analyses have generally confirmed these limitations. However, it has been further demonstrated that there are a complexity of climatic interactions across Europe which can limit production of grain maize.

A framework was developed that allowed for an integrated assessment of the effects of temperature and precipitation on grain maize. This incorporated analyses of the effects of temperature on maize phenology to define spatial and temporal (growing season) limits. Within these thermal limits a water balance model was developed and tested to study the combined effects of temperature (through changes in PET) and precipitation on maize suitability. 
(a) $+2^{\circ} \mathrm{C},-10 \%$

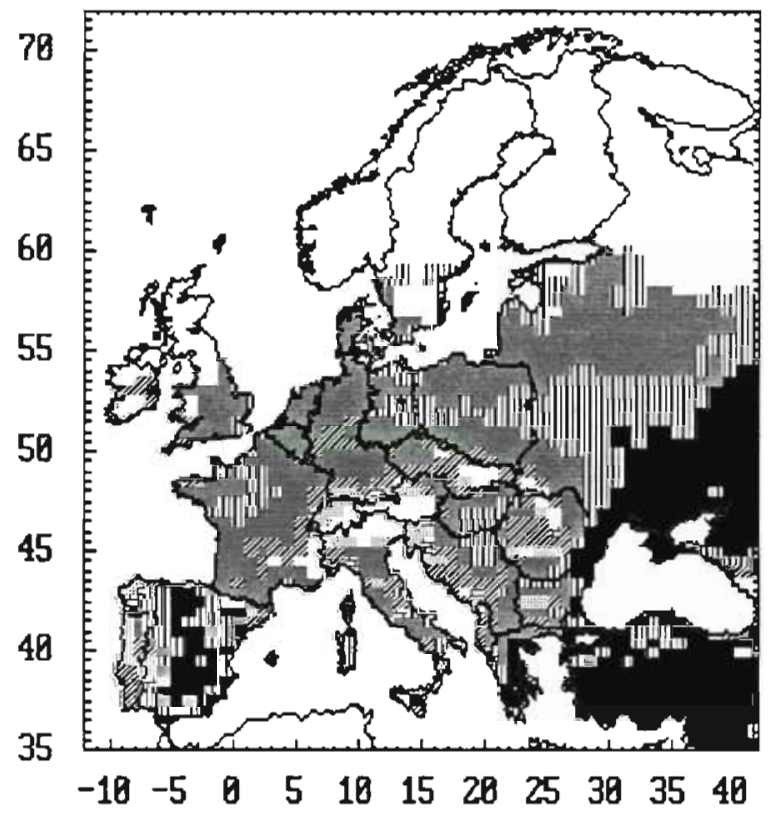

(b) $+2^{\circ} \mathrm{C},+10 \%$

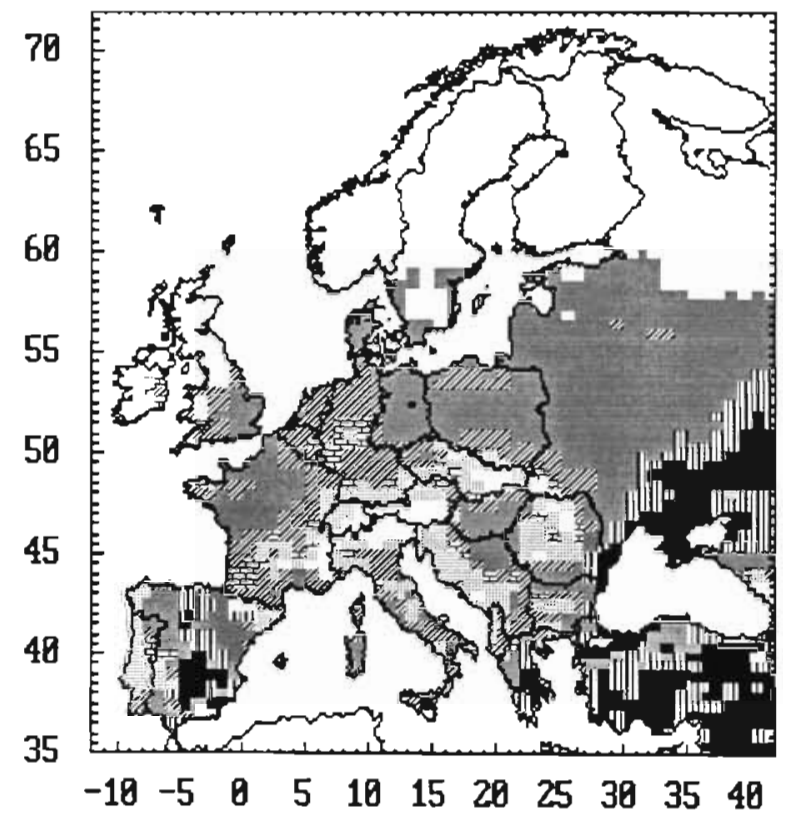

Fig. 9. Sensitivity of grain maize suitability to changes in temperature and precipitation for an adjusted sowing time: (a) $+2{ }^{\circ} \mathrm{C},-10 \%$; (b) $+2{ }^{\circ} \mathrm{C},+10 \%$

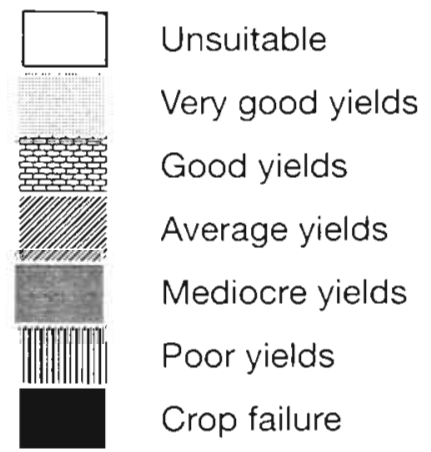

A seasonal accumulation of temperature was found to represent the current major areas of grain maize production in the EC. The margins of suitability for 3 grain maize cultivars show a significant northward shift for $\mathrm{a}+2{ }^{\circ} \mathrm{C}$ warming. Detailed analyses of the effect of temperature on phenology of early maize were made. If sowing date is not changed from the present there would be a decrease in the length of the growing season. An adjustment to an earlier sowing time would minimise the effect of increased temperature leading to little change in duration between different phases of maize development.

Results for present climate show that grain maize is already water-limited in many areas that are thermally suited. Widespread use of irrigation is made for successful maize production, particularly in southern Europe. A warmer climate will lead to increased PET of the order of $50 \mathrm{~mm}$ per $1{ }^{\circ} \mathrm{C}$ warming on average. This will increase the demand for water. However increased atmospheric $\mathrm{CO}_{2}$ could offset this effect for many $\mathrm{C} 3$ crops by increasing water use efficiency. As a C4 crop, grain maize may show relatively small improvements in water use efficiency. Coupled with these factors are uncertainties with the Thornthwaite method of estimating PET and with the changes in precipitation that may accompany a warmer climate.

A range of adjustment experiments were applied to the water balance model for a $2^{\circ} \mathrm{C}$ increase in mean temperature. These included analysis of the effect of adjusting sowing time, sensitivity to changes in precipitation $( \pm 10 \%)$ and to uncertainty in estimates of PET $( \pm 10 \%)$. A warming of $+2{ }^{\circ} \mathrm{C}$ has the same magnitude of effect on the water requirement satisfaction index (WRSI) for grain maize as a decrease in precipitation of $-10 \%$. If sowing time is not adjusted, a shorter growing season leads to a relatively lower accumulated deficit than if growing season length unrealistically remained the same. From the range of sensitivity adjustments the best result is with an earlier sowing time and an increase in precipitation. If there were no 
change or a decrease in precipitation the result could be minimal change from the present in the higher latitudes, given the tendency of the Thornthwaite method to overestimate PET relative to the Penman in these regions. In southern Europe conditions remain relatively water-limited for all sensitivity adjustments

The availability of water for irrigation is likely to be a crucial factor in determining where grain maize is grown in Europe in the future. Both areas of present and expanded thermal potential are likely to be waterlimited under a warmer climate. Those areas where there may be adequate precipitation include: the margins of high altitude regions, parts of Germany, southeast France, possibly western UK and northern Italy and some eastern European countries (parts of Czechoslovakia, ex-Yugoslavia, Romania and possibly Poland). This synopsis must be treated with caution because of the uncertainty over projections of precipitation changes.

There are clearly adaptive strategies that will be available to farmers to enable them to mitigate the negative effects (or even take advantage) of a warmer climate. A shift in the type of cultivars used could occur in present areas of maize production. A shortened and possibly drier growing season in southern Europe and a cool growing season in the north would favour earlier maturing cultivars. An earlier sowing time could be adopted as a drought avoidance strategy, possibly in combination with use of earlier maturing cultivars. This would move the timing of flowering (the most moisture sensitive phase) away from the period of peak moisture (and heat) stress. The feasibility of these strategies would be dependent on the ability of farmers to adapt their farming practices. This will be influenced by policy makers and economic forces as much as (if not more than) the climate. Changes in competitive advantage could lead to a shift away from maize production towards crops (e.g. soybean) which may be more suited to a warmer climate and increased atmospheric $\mathrm{CO}_{2}$.

It must be emphasised that the analyses in this paper have dealt with an average climatology. This has allowed for investigation of both the spatial variability in the suitability of grain maize across Europe, as well as detailed sensitivity analyses of the uncertainties. The effects of interannual variations in climate have not been explored, but it will be these non-average conditions that will largely influence the viability of grain maize production in the future, as much as they do in the present.

In addition to these factors there remains considerable uncertainty over projections of future climate. The current scientific consensus is that global mean temperatures are likely to rise by at least $1^{\circ} \mathrm{C}$ within the first half of next century (Houghton et al. 1990). However there remains considerable uncertainty over projections of precipitation, as well as other climatic variables.

Additional research will include analysis of the relative effects of climate change on different crops, an assessment of interannual variability and of the uncertainty that arises from different general circulation model (GCM) scenarios.

Acknowledgements. This study was made possible through the work of Tim Carter and Julia Porter, and in particular through the efforts of Martin Parry (Director, Environmental Change Unit). We would also like to acknowledge the support and advice of our colleagues at the Environmental Change Unit, notably Tom Downing and Paul Brignall. Thanks are also due to Paul Vossen, and the Pilot Project for the Application of Remote Sensing to Agricultural Statistics (the MARS project) of the Institute for Remote Sensing Applications for their assistance. This work was conducted for the EPOCH programme of the Commission of the European Communities (Contract No. EPOC-CT90-0031 (TSTS)).

\section{LITERATURE CITED}

Bignon, J. (1990). Agrométéorologie et physiologie du mais grain dans la Communauté Européenne. Publication EUR $13041 \mathrm{FR}$ of the Office for Official Publications of the European Communities; Series 'Agriculture'. Luxembourg Carr, M. K. V., Hough, M. N. (1978). The influence of climate on maize production in northwestern Europe. In: Bunting, E. S., Pain, B. F., Phipps, R. H., Wilkinson, J. M., Gunn, R. E. (eds.) Forage maize. Agricultural Research Council, London, p. 15-55

Carter, T. R., Parry, M. L., Porter, J. H. (1991). Climatic change and future agroclimatic potential in Europe. Int. J. Climatol. 11: 251-269

Doorenbos, J., Kassam, A. H. (1979). Yield response to water. FAO irrigation and drainage paper 33. Food and Agricultural Organization of the United Nations, Rome

FAO (1986). Early agrometeorological crop yield assessment. FAO plant production and protection paper 73. Food and Agricultural Organization of the United Nations, Rome

Goudriaan, J (1988). Landbouw en klimaat. Lucht en Omgeving, March, p. 6-8 (in Dutch)

Groenendijk, H. (1989). Estimation of the waterholdingcapacity of soils in Europe. The compilation of a soil dataset. Simulation Report CABO-TT nr. 19, CABO, Dept theor. Prod. Ecol. (Agricultural Univ.), ISRIC, Wageningen

Hellmers, H., Warrington, I. (1982). Temperature and plant productivity. In: Rechcigl, M. (ed.) CRC handbook of agricultural productivity, Vol. 1. CRC, Boca Raton, p. 11-21

Hough, M. N. (1975). Mapping areas of Britain suitable for maize on the basis of temperature. ADAS Q. Rev. 18: $64-72$

Houghton, J. T., Jenkins, G. J., Ephraums, J. J. (eds.) (1990) Climate change: the IPCC scientific assessment. Cambridge University Press, Cambridge

Jensen, M. E., Burman, R. D., Allen, R. G. (1989). Evapotranspiration and irrigation water requirements. Committee on Irrigation Water Requirements of the Irrigation and Drainage Division of ASCE, New York

Le Houerou, H. N. (1990). Global change: vegetation, ecosystems and land use in the southern Mediterranean basin by the mid twenty-first century. Israel J. Bot. 39: 481-508

Monteith. J L. (1981). Climatic variation and the growth of 
crops. Q. J. R. Meteorol. Soc. 107: 749-774

Narciso, G., Ragni, P., Venturi, A. (1992). Agrometeorological aspects of crops in Italy. Spain and Greece: a summary review of durum wheat, barley, maize, rice, sugarbeet, sunflower, soybean, rape, potato, tobacco, cotton, olive and grape. Publication EUR 14124 EN of the Office for Official Publications of the European Communities; Series 'Agriculture' Luxembourg

Parry, M. L., Duinker, P. N., Morison, J. 1. L., Porter, J. H., Reilly, J., Wright, L. J. (eds.) Agriculture and forestry. In: Tegart, W. J. McG., Sheldon, G. W., Griffiths, D. C. (eds.)

Editor: G. Esser
Climate change: the IPCC impacts assessment. Australian Government Publishing Service, Canberra, p. 2-1-2-43

Rowntree, P. R. (1990). Estimates of future climatic change over Britain. Part 2: Results. Weather 45: 79-89

Shaw, R. H. (1977). Climatic requirement. In: Sprague, G. F. (ed.) Corn and corn improvement. American Society of Agronomy, Madison, Wisconsin, p. 591-623

Vossen, P. (1989). Comparative statistical validation of two ten-day water-use models and of three yield-reduction hypotheses for yield assessment in Botswana. Agricult. For. Meteorol. 51: 177-195

Manuscript first received: April 22, 1992

Revised version accepted: August 28, 1992 